\title{
Does Supplementation by the Surgical Apgar Score Improve the Prognostic Accuracy of the Revised Cardiac Risk Index?
${ }^{1}$ Toronto General Hospital, ${ }^{2}$ St. Michael's Hospital, 3 University of Toronto, \\ DN Wijeysundera ${ }^{1,2,3}$; D Duncan 1,3, M Machina 1,3, G Tait 1,3, WS Beattie ${ }^{1,3}$
}

\begin{tabular}{|l|c|c|c|c|}
\hline Exposure & Outcome & AUC $(95 \% \mathrm{Cl})$ & P-value vs. RCRI alone & P-value vs. SAS alone \\
\hline RCRI alone & Myocardial injury & $0.73(\mathrm{Cl}, 0.70$ to 0.76$)$ & NA & $<0.001$ \\
\hline SAS alone & Myocardial injury & $0.63(\mathrm{Cl}, 0.59$ to 0.67$)$ & $<0.001$ & NA \\
\hline RCRI plus SAS & Myocardial injury & $0.77(\mathrm{Cl}, 0.74$ to 0.80$)$ & $<0.001$ & $<0.001$ \\
\hline
\end{tabular}

\begin{tabular}{|ccccc|} 
Outcome Status & Total N & $\begin{array}{c}\text { Number with Improved } \\
\text { Classification } \\
\text { (RCRI + SAS vs. RCRI) }\end{array}$ & $\begin{array}{c}\text { Number with Worsened } \\
\text { Classification } \\
\text { (RCRI + SAS vs. RCRI) }\end{array}$ & Net Improvement \\
\hline No myocardial injury & 16,658 & 1383 & 58 & $1325(7.9 \%)$ improved \\
Myocardial injury & 183 & 5 & 16 & $11(0.1 \%)$ worsened \\
\hline
\end{tabular}

\section{Background}

- The Revised Cardiac Risk Index (RCRI) is a validated instrument that uses preoperative data to predict postoperative cardiac events with moderate accuracy.

- The Surgical Apgar Score (SAS) uses intraoperative data to predict postoperative complications.

\section{Objectives}

- To determine whether combining the RCRI and SAS improves estimation of perioperative cardiac risk.

\section{Study Cohort and Methods}

- Single-center cohort study at the Toronto General Hospital (Toronto, Ontario, Canada).

- Following REB approval, electronic hospital databases were used to identify adults ( $\geq 18 \mathrm{y}$ ) who underwent major elective noncardiac surgery between 2009-2014. Intra-operative physiologic and clinical data were extracted from electronic medical records.

- Exposures:

- RCRI (range o to 6) was calculated using preoperative information and performed surgery.

- SAS (range o to 10) was calculated using blood pressure, heart rate and estimated blood loss.

- Outcome: 30-day in-hospital myocardial injury (troponin I elevation above $99^{\text {th }}$ percentile)

- Correlation between RCRI and SAS was calculated using Spearman rho.

- Area under curve (AUC) of the receiver operating characteristic (ROC) curve was used to compare prediction of myocardial injury by the RCRI vs. SAS.

- Reclassification measures (risk strata <1\%, I-5\%, 5-10\%, $>10 \%$ ) and AUCs were used to determine whether combining the RCRI and SAS improved risk prediction.

\section{Results}

- The study cohort included 16,841 patients of whom 183 (1.1\%) had myocardial injury.

- The proportions with RCRI scores of $0,1,2$ and $\geq 3$ were $46.5 \%, 38.9 \%, 11.3 \%$ and $3.3 \%$ respectively.

- The proportions with SAS of 0-2, 3-4, 4-5, 6-7, 7-8, and 9-10 were $0.5 \%, 4.4 \%, 21.3 \%, 55.3 \%$ and $18.6 \%$ respectively.

- The correlation between the RCRI and SAS was poor (rho $0.13 ; 95 \% \mathrm{Cl}, 0.12$ to 0.15 )

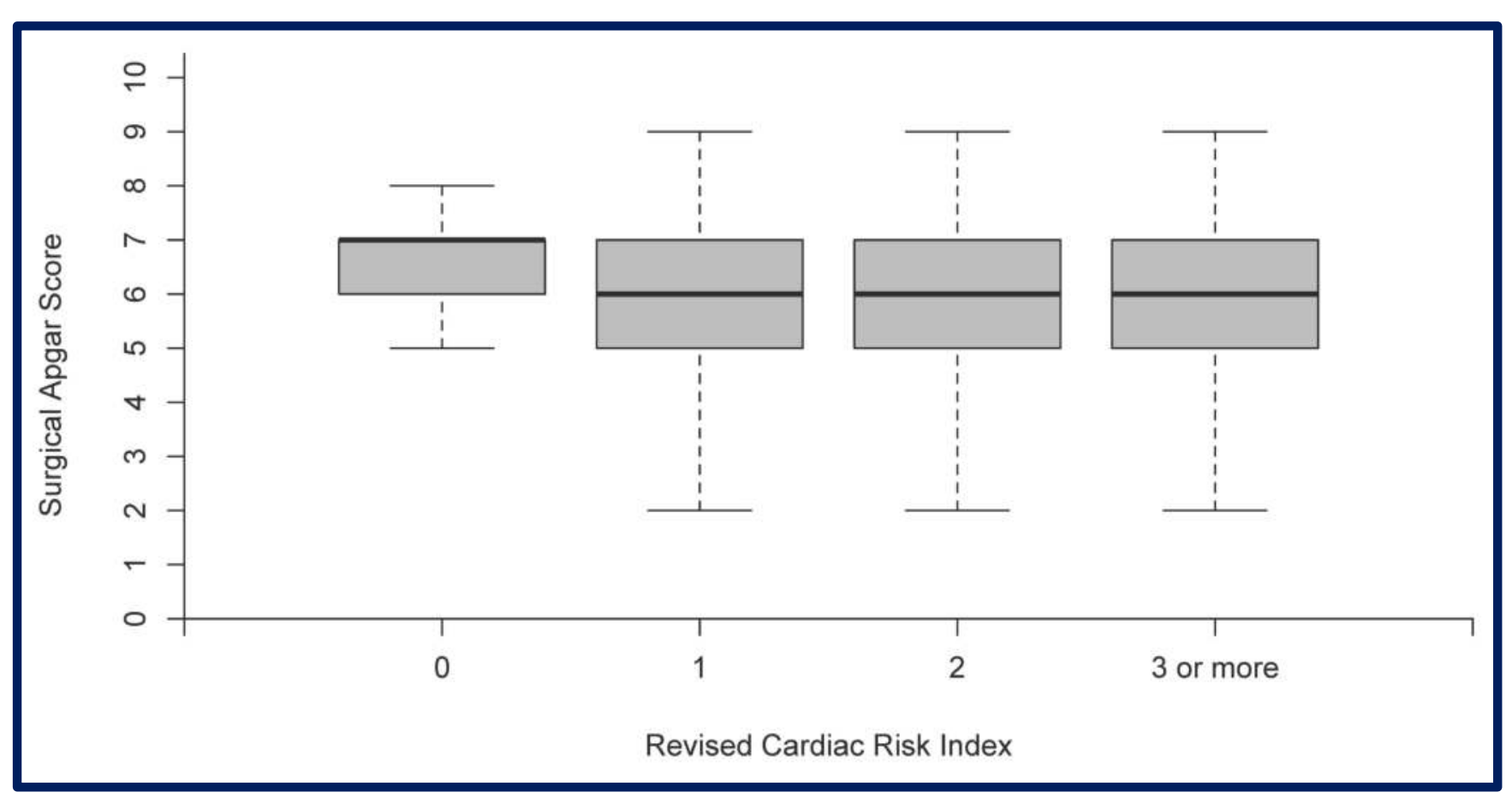

- The RCRI had better discrimination than the SAS $(P<0.001)$.

- The combination of the RCRI and SAS had better discrimination than the RCRI alone $(P<0.001)$.

- Overall, a net 1314 individuals (7.8\%) in the cohort had with improved classification of risk when the SAS was combined with the RCRI.

\section{Conclusions}

- Supplementation of prognostic information from the preoperative-based RCRI with risk estimates from the intraoperative-based SAS improves prediction of risk.

- The improvement in risk prediction is largely driven by better risk assessment among individuals who do not suffer postoperative myocardial injury. 